\title{
Software is Eating the Software That's Eating the World
}

\author{
Jon Eckhardt (University of Wisconsin-Madison)
}

KEYWORDS: Information, Software, Data, Information

Technology, Technology Commercialization.

In 2011, Marc Andreessen famously wrote a prescient claim that "software is eating the world." His prediction was that software companies would disrupt traditional industries and since then, we've seen industries transform and companies fold in response to Amazon, Netflix, Airbnb, and more.

Another wave of disruption is building with important implications for entrepreneurs, investors, and consumers. It is time to expand on Marc Andreessen's maxim that software is eating the world:

Software is eating the software that is eating the world.

This benefits consumers but creates challenges for entrepreneurs who aspire to build durable value.

Software companies that initially gained traction by reducing complexity in either traditional industries or older software products are now facing the threat of disruption from startups that reduce complexity even further. Many of these newer companies are building easy-to-use software infrastructure that is fundamentally disruptive to the prior generation of disrupters. This dynamic is apparent in the rise of companies like

Airtable,

(http://www.airtable.com/)

Squarespace

(https://www.squarespace.com/) and Shopify(https://www.shopify.com/) that are
disrupting software companies that proceeded them.

\section{Meet the New Disrupters}

Airtable launched in 2015 as an application that shifts the process of creating a relational database from the realm of the software developer into the realm of the average computer user. The application offers a variety of use cases, from building a custom project tracker to creating a bespoke sales CRM. With compelling

integrations, it threatens to erode the value proposition of numerous established software-as-a-service applications.

With Airtable, it's easy for a computer-savvy person to build their own version of Trello or Salesforce. It's easy for a team to whip up an event planning app, or a commercial real estate management platform. And with over 30,000 companies using Airtable, including Tesla and Airbnb, Airtable has significant momentum. Relational database platforms that required SQL programmers to implement have been disrupted by Airtable's software that builds software upon software.

A similar process played out in website development software. WordPress automated back-end website coding, allowing tech-savvy users to focus on front-end web design. Squarespace, Square, Shopify, and similar service providers such as Weebly automate the backend coding and much—or all—of the design work. This allows the average user to launch a beautiful website regardless of development or design skills. Importantly, the early leaders in this space have been supplanted by simple yet powerful tools built upon other software.

Both Airtable and Square found a market opportunity by reducing the complexity of completing tasks such as creating a relational database or building a welldesigned website. And both Airtable and Squarespace compete with more established choices, which initially gained momentum by reducing the complexity of even older software products or pen-and-paper methods.

\section{Building Durable Value}

Look at each level of the food chain and the pattern repeats itself. Customers will move to products that further remove complexity unless given a compelling reason to stay. It is not enough to simply reduce the complexity of existing technology. To build durable value, businesses must offer something else that sets them apart. Academic research asserts that the path to durable value lies in building internal capabilities and

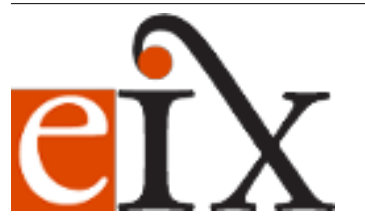

Copyright ( ) 2021 The Authors. Entrepreneur \& Innovation Exchange is published at EIX.org. This is an open access article under the terms of the Creative Commons Attribution-NoDerivs License, which permits use and distribution in any medium, provided the original work is properly cited and no modifications or adaptations are made. View EIX.org Authorship Terms at https://eix.org/terms 
strategic assets -- such as customer relationships, sticky contracts, and switching costs -- that are valuable to customers and difficult for competitors to emulate. The challenge is to build these durable advantages while also reducing complexity for users.

The software companies that can build a deep moat around themselves will have a greater chance of success in the long run. Those that rely solely on reducing the complexity of a previous dominant software choice are more likely to be replaced by more powerful and less complex versions of themselves.

This dynamic raises questions for software entrepreneurs and investors alike:

- Software entrepreneurs, are you focusing solely on building software that meets the needs of your customers through transactional relationships, or are you building durable relationships with your customers that will lead to lasting value?

- Investors, are you investing in companies that solely excel at implementing technology to solve immediate problems, or are you backing creators of technologies with the potential to become integrated into the lives of their clients? Is your cash-on-cash math cognizant of what might be next?

- Reducing complexity for customers opens the door to building great companies by enabling customer acquisition.

The answers to those questions may help predict whether a given software company ultimately eats or is eaten. 